 \\ z Filologii Polskiej i Słowiańskiej
}

Вадим Юрьевич Меликян

(Южный федеральный университет,

Ростов-на-Дону - Таганрог)

Анна Васильевна Меликян

(Южный федеральный университет,

Ростов-на-Дону - Таганрог)

\section{Феномен синтаксической семиоимпликации}

В содержательной структуре конкретного высказывания различаются семантический (когнитивный) и прагматический (в широком смысле) аспекты. Это обусловлено особенностями человеческого сознания: «Психическая деятельность опирается на координированное единство прагматических и когнитивных структур сознания» (Никитин, 1988, c. 20). Эти структуры заполняются опытом всего человечества, а также собственным опытом индивида, скорректированным благодаря языку социума. При этом «исходными являются прагматические структуры сознания, отвечающие за субъективную оценку всего наблюдаемого и переживаемого человеком с точки зрения его интересов и ценностной ориентации в мире» (Никитин, 1988, с. 20). Всякая мысль характеризуется как элемент этих двух структур сознания, что и приводит к рас-

This is an Open Access article distributed under the terms of the Creative Commons Attribution 3.0 PL License (creativecommons.org/licenses/by/3.0/pl/), which permits redistribution, commercial and non-commercial, provided that the article is properly cited. () The Author(s) 2018.

Publisher: Institute of Slavic Studies, Polish Academy of Sciences

[Wydawca: Instytut Slawistyki Polskiej Akademii Nauk] 
слоению значения на указанные выше аспекты. Первый представляет собой информацию о мире вне субъективной оценки индивида. Второй является носителем информации о субъективном отношении к означаемому факту.

Различаясь по своей природе, эти компоненты значения тесно связаны между собой, «так как различие в субъективной ценности вещей, явлений, событий для человека коренится в различии их объективных свойств» (Никитин, 1988, с. 21).

Особенно ярко наличие этих двух компонентов значения проявляется в конструкциях с так называемым семиоимпликационным значением (если пользоваться термином М. В. Никитина, употребляемым им применительно к лексемам). По выражению М. В. Никитина, это значения, которые представляют собой «выводное знание ... из конкретных ситуаций употребления знаков» (Никитин, 1997, с. 7). В синтаксисе к конструкциям с таким значением следует отнести те из них, которые наряду с кодифицированной семантикой употребляются с выводимым из нее значением, что возможно только в том случае, если за ним стоит отправитель с определенной речевой интенцией.

Типичным случаем семиоимпликационных значений в синтаксисе представляется употребление позитивных конструкций в значении негативных и наоборот. Некодифицированное (конверсивное, по терминологии Б. П. Ардентова, 1976) значение в этом случае вторично, хотя обязательно, и опирается на семантику и способы ее выражения кодифицированного типа. Так, для семиоимпликаций позитивных по форме структур типично употребление глагольных форм, несущих модальное значение ирреальности (буд. время, сослагат., повелит. накл., инфинитив), а также вопросительная целеустановка, сигнализирующая о незнании говорящим, существует ли факт, о котором он сообщает, в реальной действительности. Эти условия, тем не менее, не исключают обязательного указания в виде так называемых коммуникем (Меликян, 2014, с. 87) и т.п. на то, что говорящий «вступает в игру», навязывая синтаксической конструкции импликативные значения. Основные условия такой семиоимпликации и виды языковых средств, указывающих на ее возникновение, и рассматриваются в данной статье. Кроме того, обращается внимание на способы выражения разнообразных коннотаций, органически связанных с самим процессом семиоимпликации синтаксических структур и закономерно порождаемых ею. 
Как справедливо отмечает Ноуэлл-Смит, «для всевозможных вторичных употреблений предложения практически нет логических ограничений; во многих случаях человек достигает своей цели, преднамеренно употребляя предложение необычным образом или даже употребляя его в смысле, противоположном обычному, иронически» (Ноуэлл-Смит, 1985, с. 173).

Большинство предложений, сопровождаемых особой интонацией, в определенном контексте может подвергаться конверсии в плане негопозитивности: «Естественно, что ироническое отрицание может скрываться вообще за всяким, по сути дела, предложением» (Шмелев, 1958, с. 75).

Подобным конструкциям присущ «двойной антропоцентризм» их содержания, который проявляется в стремлении говорящего убедить собеседника в наличии факта, противоположного устоявшимся представлениям реципиента. Это основное, информативное значение всегда сопровождается дополнительными субъективно-модальными оценочными наслоениями, которые реализуются, как правило, в виде эмоционального неприятия факта, о котором сообщается в высказывании (огорчение, удивление, экспрессия возмущения и т.п.). Кроме того, очень часто отрицание факта и его негативная оценка сопровождаются отрицательной оценкой и лиц, имеющих отношение к данному факту - часто самого собеседника. Например: - Тебе ли, тебе ли, Лиза, мне так говорить? - увлекся я, наконеи, полньм негодованием («не тебе...») /Ф. Достоевский. Подросток/.

В качестве ядра семиоимпликационных структур выступают конструкции, способные выражать оба значения: прямое и переносное (т.е. противоположное). Мы обозначили их термином «симметричные» конструкции. В роли периферии («несимметричных» конструкций) - модели предложений, которые обладают одним значением, противоположным форме, выражающей его, а также модели, противоположные по знаку, но несоотносимые по каким-либо морфологическим параметрам. Их моносемантичность закреплена на морфолого-синтаксическом уровне организации предложения.

В русском языке выделяются, с одной стороны, специализированные модели предложений, которые обладают какими-либо языковыми средствами, облегчающими их переосмысление на противоположные. С другой - неспециализированные, которые такими средствами не обладают. Для 
специализированных построений выражение семиоимпликационного экспрессивного значения узуально.

Неспециализированные синтаксические модели могут быть лишены каких-либо особых формальных показателей, которые способствовали бы их более лёгкому переосмыслению в анализируемом нами аспекте. Они характеризуются нейтральным словопорядком. Для таких построений выражение противоположного, вторичного значения является окказиональным и неспецифичным. Например: - Мам, ты гляди-ка, што он вытворяет - за шубу-то начал обзывать по-всякому! ... - Ть что это, Вениамин? - сказала она [теша] с укоризной. - Другой бы муж радовался... - А я и радуюсь! Я до того рад, что хоть впору заголиться да улочки две дать по селу - от радости /В. Шукшин. Мой зять украл машину дров!/; Ср. - Тьь радуйся, что все живы и здоровы. - А я и радуюсь! /Из разг. речи/. Весь груз ответственности за переосмысление значения таких предложений на противоположное ложится на контекст. При этом вторичное значение способно реализовываться лишь в контексте «конфликта», обиды говорящего. Например, фразеосхема «А то + Pron + не + V!» (Меликян, 2016, с. 18): [Сьн:] - Значит, я должен тебя изучить: характер твой, повадки, походку... Все выходки твои, как у нас говорят. [Oтеи:] - A то ты не знаешь? [Сын:] - Я к примеру говорю («ты их знаешь...») /В. Шукшин. И разыгрались же кони в поле/.

Несимметричность негопозитивных синтаксических конструкций может иметь структурно-семантический характер. Это построения, форма и содержание которых не совпадают. Они являются утвердительными или отрицательными по форме, но не по содержанию. Значение, используемое в данной коммуникативной функции предложения, может быть единственным, то есть не имеющим противочлена. Например: «V finit (буд. вр., с.в.) + тут [здесь, там, у вас, ...]» (Меликян, 2016, с. 239): - Нечего мне думать! Ть хитрить хочешь. - Нахитришь у вас! («не нахитришь + негат. отношение») /А. Писемский. Богатьй жених/. Значение данного предложения может варьироваться, но не способно кардинально изменять своё содержание. Смысл высказывания негативен и по этому признаку противоположен позитивной структуре, выражающей его.

Структурно-семантическая несимметричность может осложняться дополнительными грамматическими факторами, усиливающими характер асимметрии такого предложения. Например, «Pron 1 + тебе [вам, ему, ей, им] +<не > + V finit (б. вр.)!» (Меликян, 2016, с. 219): [Дарья Васильевна:] 
А ты не ори. Я тебе, брат, поору. Я не посмотрю, что ты пробессор /Б. Ромашов. Великая сила/. Кроме знакового противопоставления позитивного по форме высказывания негативному его содержанию («не ори + угроза»), здесь присутствует несовпадение противопоставляемых категорий по типу значения объективной модальности: форма высказывания характеризуется наличием синтаксического значения изъявительного наклонения будущего времени, а коммуникативный смысл - побудительный.

Семиоимпликационные структуры с глаголом в форме будущего времени симметричны в плане негопозитивности конструкциям кодифицированной семантики: - Да, какже! - отвечает Ваня. - Так я и буду бегать из угла в угол («не буду бегать...») /Гл. Успенский. Невидимка Авдотья/; Ср. - Так я и буду бегать из угла в угол, пока меня кто-нибудь не сменит («буду бегать...»).

Такие конструкции способны выражать оба противоположных значения. Это построения с потенциальной спещиализацией. Например, «V finit (б. вр.) + Pron $_{1}+<\ldots$..>!» (Меликян, 2016, с. 289): - Буду я там из-за каких-то стульев ездить! («не буду...») /А. Макаренко. Педагогическая поэма/; Ср. - Буду я работать каждый день, пока не зашишу диссертаиию («буду...») /Из разг. речи/.

Каждое из подобных предложений обладает системой противоположных значений, позволяющих прогнозировать ситуацию его речевого употребления. Данные синтаксические построения представлены системой моделей, их модификаций, вариантов, характеризующих структуру этих языковых единиц. При этом переосмысление их значения эффективно идет в обоих направлениях: как со знаком «-», так и «+» (- Только (не) сделай это! Пожалеешь!; Ср. - Только (не) сделай это! Умоляю!).

Структурно-семантическая несимметричность может быть обусловлена характером семантики глагола-сказуемого, то есть реализоваться на обобщенно-лексическом уровне модели предложения. Например: [Хорочилин:] - Hy, ты похамишь! («не будешь хамить...»)/К. Тренёв. Навстречу/; Ср. - Ну, ты отдохнёшь! Как бы не так! Всю ночь пахать будешь! («не отдохнёшь...») и - Нy, ты отдохнешь! Времени у нас будет предостаточно! («отдохнёшь...»). В рамках данной конструкции не могут быть использованы в своём прямом значении слова, выражающие позитивный, с точки зрения говорящего, факт, ибо основная функция данных конструкций - запрет, угроза, требование прекратить 
какое-то отрицательное с точки зрения говорящего действие-состояние (например: - Ты у меня пообзываешься!, - Ты у меня покидаешься камнями! и т.п.).

Сущность таких языковых единиц заключается в том, что противопоставление их значений в плане негопозитивности идёт по линии негации, и такие значения оказываются прямо противопоставленными друг другу. Одно из этих значений выражает при помощи различных языковых средств наличие связи между элементами высказывания, другое - отсутствие такой связи. Последнее предполагает убеждённость адресата в наличии факта, прямо противоположного излагаемому, или отсутствие этого факта. Таким образом, в качестве основного экстралингвистического условия употребления негативных конструкций в речи выступает знание об убеждённости собеседника в существовании положительного факта, соответствующего отрицаемому. Отрицание факта предполагает присутствие в сознании говорящего позитивной установки собеседника в отношении этого же факта. Поэтому отрицательные конструкции исконно полифоничны (Он не пришёл, я знаю; Вы думаете, что он пришёл; Я утверждаю, что он не пришёл). Видимо, поэтому так охотно используется «маска» утвердительной конструкции для выражения отрицания. Передаваемая информация в таких случаях - это повторение того, что заложено в сознании собеседника, но повторение-«маска», которая используется для негации, содержащей ещё и иронию, сарказм в отношении того, в чём ошибочно убеждён собеседник.

Способность использоваться в качестве восклицательных такие конструкции приобретают благодаря некоторым структурным особенностям их реализации в речи, а также изменению их коммуникативной направленности. Так, большинство из этих моделей представляет собой усеченный, неполный вариант аналогичной утвердительной конструкции. Например: - Писать книги! Что может быть интересней! («положит. оц., одобрение...») и - Писать книги! Что может быть более скучным! («негат. оц., неодобрение...») /Из разг. речи/. В одном случае анализируемые восклицательные конструкции оказываются лишь каким-либо членом соответствующего повествовательного предложения (Писать книги интересно/неинтересно), в другом - представляют собой одну из частей сложного предложения.

По-видимому, подобная «эллиптичность» данных конструкций создает напряжение в речевой ситуации и открывает дополнительные 
возможности для функциональной и семантической трансформации предложений, порождая их синкретизм.

Значение запрета может быть выражено повелительным наклонением, например: - Кричи еще иибче, чтоб соседи услыхали, коли стыда в тебе нет /А. Островский. Пучина/. Данная конструкция выражает оба компонента значения - информативный и оценочный: «не кричи + возражение, осуждение...», т.е. «бессовестная, не кричи...». Это обусловлено полностью соответствующим контекстом. В целом же часто бывает очень трудно определить характер соотношения диктума и модуса в семантической структуре предложения и заявить о том, что в каком-либо конкретном высказывании они занимают равноправное положение.

Использование позитивных побудительных конструкций в значении отрицательных объясняется теми «скрытыми» заключенными в них смыслами, которые актуализируются в определенных контекстах. Дело в том, что утвердительные побудительные предложения, кроме побуждения, содержат еще и информацию об отсутствии данного действия в реальной действительности; отрицательные же побудительные предложения - информацию о наличии действия, которое говорящий побуждает собеседника прекратить: - Беги! Попробуй только! (в знач.: «не беги...»). Отсюда появляется возможность актуализировать данные скрытые значения за счет контекста. Например, «V imper + у меня [мне] + ещё [тут, здесь]!» (Меликян, 2016, с. 241): [Круглова:] Много очень воли ты забрала. [Агния:] Заприте. [Круглова:] Болтай ещё! («не болтай...») /А. Островский. Не всё коту масленица/.

Достаточно легко приобретают семиоимпликационное значение модели предложений и со сказуемым в форме условно-сослагательного наклонения, например: - A то будь она на хорошем счету - не нашелся бы никто до двадизати шести лет! Эка!... («нашелся бы...») /В. Шукшин. Чередниченко и иирк/; Ср. - А если не нашелся бы никто, тогда что! («не нашелся бы...»). В данном случае ирреальность действия в прошлом предполагает его отсутствие.

Запрет может быть связан с уровнем лексического наполнения. Например, «Ты [он, она, они] + мне [нам, ему, ей, им] + <не $>+$ V finit (б. вр.)!» (Меликян, 2016, с. 219): - Ты у меня поплачешь! Я отобью у тебя желание так шутить! («будешь плакать...»); Ср. - Ты у меня поплачешь при людях! Приедем - я с тобой разберусь! («не будешь плакать...»). Лишь слова, обозначающие разного рода нежелательные для говорящего дей- 
ствия, могут способствовать формированию обоих противоположных значений. Например: - Рассердился дед, повернулся к Мишке: - Я тебе, окаянный, прости, господи!... Постучи у меня, я те стукну! («не стучи + угроза...») /М. Шолохов. Нахаленок/; Ср. - Постучи у меня в мастерской, а здесь не мешай людям отдыхать («постучи...»).

В языке также существуют предложения, специализация которых в сфере негопозитивности обусловлена наличием в их составе энантиосемичных лексических или фразеологических единиц. Это уровень речевой реализации синтаксической модели. Например, «Есть + что 1-6 [кто $\left.{ }_{1-6}\right]$ + V inf!» (Меликян, 2016, с. 250): - Есть об чем жалеть! И без них тоска смертная! («не о чем жалеть...»)/А. Островский. Доходное место/; Ср. - Есть о чем жалеть! Такую возможность упустили! («есть о чем жалеть...»)/Из разг. речи/. В данных высказываниях слово есть реализовано в своих противоположных значениях, что повлекло за собой и переосмысление значения всего предложения.

Появление семиоимпликационных значений в сфере негопозитивности - типичное явление и для вопросительных общемодальных, и частно-диктальных (с общемодальным оттенком) предложений.

В семантику таких предложений неизбежно входит компонент «незнание говорящим, существует ли факт, представленный в предложении, в реальной действительности». Отсюда в сознании говорящего появляется предположение об одинаковой возможности наличия или отсутствия передаваемого им факта.

Структурно-семантическая асимметрия может осложняться функииональной несимметричностью поверхностной и глубинной структур. Например, «Кому + Pron $_{1}\left[\mathbf{N}_{1}\right]+$ V(?)!» (Меликян, 2016, с. 255): - Вон какие люди хворают, да и то к врачам ходют, а он, видите, не может заднииу свою показать. Кому она нужна к иёрту!... там глядеть не на что... («никому не нужна + осуждение действий собеседника...») /В. Шукшин. Операция Еøима Пьяньх/. В данном примере, кроме структурно-семантической асимметрии, обнаруживается и несовпадение формы и функциональных характеристик содержания: вопрос - утверждение. Прямое (вопросительное) и переносное (утвердительное) значения не сводимы в одну оппозицию противоположных значений ещё и потому, что данное предложение в прямом значении абсурдно по своему содержанию, за счет наличия оборота $\kappa$ черту, несмотря на грамматическую и логическую правильность в остальном. 
Различные причины накладывают запрет на использование таких конструкций в первичном, совпадающем с формой по знаку, значении. В качестве таких причин выступают следующие факторы. Прежде всего структурно-семантическая асимметрия может быть закреплена за самой синтаксической конструкцией, что делает невозможным дальнейшую семантическую трансформацию подобных фразеологизированных образований. Например, формы прошедшего времени глагола найти в конструкции «Нашёл $(-\mathbf{a},-\mathbf{n})+<$ себе $>+\mathbf{N}_{4}$ !» (Меликян, 2016, с. 100) приобретают особое значение, уже далёкое от исходного значения данного глагола вообще: «5. ... 2) ...выражение насмешливого отрицания, утверждения противоположного. - Нашёл дурака! (то есть «Я - или тот, о ком идёт речь, - не дурак») (Ожегов \& Шведова, 1994, с. 374). Например: - Пойду сала под кожу кое-кому залью, - сказал он. [...] «Нашли дурачка... Сволочи. Еще по милищиям бегает!» («я не дурак, и не буду делать кем-то предлагаемого + возмущение, негодование...») /В. Шукшин. Мой зять украл машину дров!/. «В подобных случаях, - как справедливо отмечает Д. Н. Шмелев, - значение конструкции становится синтаксически обусловленным. Оно не вытекает прямо и непосредственно из значения глагольной формы, а как бы строится на основе определённой и устойчивой «модели», представляя собой синонимическую замену отрицательной конструкции...» (Шмелев, 1958, с. 74). Это делает, в свою очередь, нерелевантным характер лексического наполнения синтаксической конструкции. Такая структура становится специализированной моделью предложения для выражения строго определённого значения: негативного или позитивного (плюс отрицательная эмоциональная оценка). Эта специализация, таким образом, заложена на абстрактном уровне ее организации и её обобщенно-лексического содержания.

Часто используются внешнеконтекстные условия типизированного типа. Сюда относятся коммуникемы, часто имеющие форму самостоятельных предложений: Жди!, Дожидайся!, Надейся!, Держи карман шире!, Как же!, А то!, Как бы не так! и т.п. (Меликян, 2013). Например: - Думаю: повысили его, что ли?! - Дожидайся, повысят! Скорей повесят. - Ха-ха-ха!... (отрицание...») /В. Шукшин. Позови меня в даль светлую/.

$\mathrm{C}$ парадигмой прошедшего времени некоторые из коммуникем не употребляются, видимо, в силу своего исходного лексического значения: Жди!, Надейся!. Ждать, надеяться можно только на что-то, что должно совершиться в будущем. Таким образом, возникает еще одна проблема 
- выявление соотношения коммуникем с определенным членом парадигмы предложения-высказывания. В зависимости от формы времени глагола-предиката меняется и направленность оценки. Прошедшее время связано с оценкой ситуации, данной в предложении, будущее - с оценкой содержания предшествующей реплики.

Видимо, синкретичная модель перестает быть таковой, если в состав ее ввести коммуникему, переводящую её из сферы позитивных моделей в сферу негативных. Графически коммуникемы чаще всего отделяются от предложения основной модели точкой или восклицательным знаком, но фактически связаны с его семантической структурой. Следовательно, проблема синтаксической переходности неразрывно связана с другой глобальной проблемой - тождества и отдельности предложения-высказывания, а также с выявлением всего арсенала коммуникем в русском языке, резко меняющих значение высказывания.

У каждого из типов противоположности, предметной или оченочной, существуют свои собственные средства специилизации. У конструкций с предметным типом противоположности в сфере негопозитивности это, как правило, предикаты, предполагающие формы ирреальных наклонений или формы будущего времени (или прошедшего в значении будущего), которые, как известно, выражают отсутствие действия в реальной сиюминутной действительности; использование общемодальных вопросительных конструкций (характеризующихся семантикой, предполагающей незнание говорящего о том, существует ли сообщаемый им факт в действительности), а также построения с обратным порядком слов, у которых предикативно значимый компонент вынесен на первое место. Например: - Черта с два, - угрюмо подумал он. - Как же, заболеют они! («не заболеют...») /Стругацкие. Парень из преисподней/; Ср. - Боюсь, заболеют они («заболеют...») /Из разг. речи/. Как видим, предложение Заболеют они! в первом случае употреблено в переносном, негативном, значении, осложненном коннотацией иронии, во втором - в прямом, позитивном. Бо́льшая потенциальная возможность, чем у других синтаксических конструкций, выражать оба противоположные значения формально выражена здесь обратным порядком слов, который свидетельствует об особом коммуникативном замысле говорящего (собеседнику обычно нет необходимости просто повторять предшествующую реплику).

В сфере оценочных предложений в роли средств их специализации чаще оказываются различные местоименные и наречные лексические 
компоненты, выполняющие функцию частиц и обладающие абстрактной, отвлечённой семантикой, а также междометия (они обычно являются частью вопросительных и восклицательных синтаксических моделей). Данные языковые средства в силу различной степени неопределённости их семантики облегчают переосмысление содержания анализируемых построений на противоположное. Например: - Что за сапожки, просто чудо! Так бы взял да примерил. («положит. оц...») /В. Шукшин. Сапожки/; Ср. - Прошу вас, не мешайте мне, - попросила она и медлительно сдунула волос со щеки, встретив глазами грустный взгляд Кондратьева. - Что за человек! Это я вам мешаю? - раздражённо загудел голос полковника («негат. оц...») /Ю. Бондарев. Батальоны просят огня/.

Неспециализированные конструкции представляют собой обычные синтаксические построения, которые лишены каких-либо формальных показателей (структурных, морфологических или лексических), способствующих их более лёгкому переосмыслению в анализируемом нами аспекте. Они характеризуются нейтральным словопорядком. Для таких построений выражение противоположного, вторичного значения является окказиональным и неспецифичным. Для их переосмысления требуются дополнительные контекстуальные условия, определенное лексическое содержание конструкций, например: [Гребенщиков:] Неужели без суда нельзя было договориться? Заплатили бы вам за баню... [Ефим:] Это уж ты сам с ней договаривайся, может, сумеешь. Я не мог. Мне этот суд нужен... как собаке пятая нога («не нужен...») /В. Шукшин. Суд/ и - Большая у меня охота побеседовать с тобой эдак, знаешь, открыто, без многоточий, очень это нужно мне, да вот всё мешают! («нужно...») /М. Горький. Жизнь Клима Самгина/. Слова-предикаты с модальным значением «нужно, необходимо» легко приобретают противоположные их структуре негопозитивные значения, так как нужда в чем-то одновременно означает и отсутствие этого «чего-то» в реальной действительности и одновременно позитивный факт нуждаемости в этом «чем-то».

Подобные переосмысления могут испытывать и безличные предложения, например: - Нужно мне беречь их для приданого, - разве я буржуй? /В. Беляев. Старая крепость/; Ср. Нужно мне было рассмотреть эту Таню как следует. /В. Аксенов. Пора, мой друг, пора/.

Преобразование позитивной конструкции в негативную может сопровождаться: а) негативно-оценочным значением, сориентированным на предшествующую реплику (- А то они заблудятся!; - Так он тебе 
и сказал!); б) негативно-оценочным значением ситуации, содержащейся в самом высказывании (- Куда вы прёте напролом?!; - Ты ещё побалуешься!).

Высказывание из позитивно-оценочного может быть преобразовано: а) в негативно-оценочное (- Хорош друг!); б) высказывание в зависимости от контекста может быть в одном случае использовано как негативное, а в другом - как негативно-оценочное (- Какой праздник!). То есть синкретизм семантики предложений в русском языке может сопровождаться одновременным преобразованием двух или нескольких значений, преобразованием одного значения (совмещенностью в одной форме-модели двух противоположных значений), преобразованием одного по форме предложения в зависимости от контекста в отрицательное высказывание или же в высказывание позитивное, но имеющее негативно-оценочное значение: то есть в последнем случае одной синтаксической модели могут соответствовать три высказывания в речи.

Подобные конструкции с семиоимпликационным значением следует отличать от конструкций, противоположное значение которых в сфере негопозитивности не выводится из их основной семантики, а является «отголоском» значения их полного варианта. Сами же они - результат элиминации или редукции одного из его членов, чаще всего с модально-оценочной семантикой. Свидетельство этого - аграмматические явления в структуре таких конструкций: несвойственное тем или иным глаголам управление, асемантические связи и отношения словоформ и т.п.

Однако и в этих конструкциях налицо элемент выводимости, определяемый контекстом и поддерживаемый ирреальной семантикой предиката, чаще всего в форме будущего времени или повелительного наклонения, ибо они часто омонимичны конструкциям с прямым значением, которые характеризуются закрепленными в языке кодифицированными связями и отношениями словоформ.

Таким образом, семиоимпликационные значения возникают здесь как результат процесса выводимости, как вторичного процесса, возможного только в результате элиминации её модусных звеньев. При этом и полный вариант таких конструкций содержал отрицание лишь в скрытом виде, имплицитно: - Побегай еще - получишь (поплатишься) y меня! $\rightarrow$ - Побегай еще у меня! Обе конструкции по значению одинаково негативны и содержат запрет («Не бегай!») и обе сопровождаются дополнительной коннотацией угрозы наказания, расплаты, выраженной 
во втором случае резко и категорично. Следует заметить, что аграмматичность сочетаемости, возникающая как результат элиминации компонентов, - общесинтаксическое явление, наблюдаемое и на уровне простого предложения и словосочетания. Ср. «поехать на картофель», «приехать с кукурузы» вместо «поехать на уборку картофеля», «приехать с прополки кукурузы», где элиминация отвлеченного существительного порождает аграмматичное управление, несвойственное литературному языку; причем неэлиминированное существительное приняло не свойственную ему в данном контексте форму элиминированного, изменив родительный падеж на винительный. То же наблюдается и в исследуемых здесь конструкциях с элиминацией предиката (- Я тебе еще поговорю!), где форма 1-го лица заимствована от элиминированного глагола задам: - Я тебе задам, если еще будешь разговаривать! Исчезнув, глагол задам оставил в наследство глаголу поговорить свою форму лица и свою зависимую словоформу тебе, а сложное предложение превратилось в простое. Таким образом, перед нами конструкции, имеющие исходный вариант.

Подобные конструкции в силу своей аграмматичности не имеют соответствий среди кодифицированных структур и этим отличаются от конструкций, появление семиоимпликационных значений, в которых лишь требует определенных контекстуальных условий и не требует изменения их формы.

Если совпадения и возможны иногда, то они чисто случайны и различаются не только значением негопозитивности, но и семантикой своих компонентов. Ср. - Ты у меня еще погуляешь! («не погуляешь...»). В свободном употреблении данная фраза имеет позитивное значение, а оборот у меня указывает на место действия.

Негативной конструкции соответствует полный вариант: - Tbl, если еще погуляешь, поплатишься у меня! То есть лексически выраженная угроза элиминируется, а во фразе, ставшей более динамичной, напряженной после элиминации, эта функция передана интонацией с повышением тона в конце.

Запрет на использование предложения в прямом значении может подкрепляться причинами грамматического порядка. Например, «V imper + у меня [мне] + ещё [тут, здесь]!»: Фельдшер вспьлил и крикнул: - Поговори мне ещё! Дубина... /А. Чехов. Скрипка Ротшильда/. Предложение используется только в негативном своём значении: «не говори (не разговаривай, замолчи)...». Это обусловлено применением не свойственного 
данному глаголу управления (необычностью подчинённой местоимённой словоформы: поговорить с кем?, но не кому?).

За моделью « Pron $_{1}+$ тебе [вам, ему, ей, им] + <не $>$ + V finit (б. вр.)!» закреплено только одно значение: «запрет с оттенком угрозы». Но этот запрет часто соответствует этическим нормам этноса: «не дерись, не хами, не балуйся» и т.п. Например: [Становой грозя:] Я тебе поговорю! («не разговаривай, не хами + угроза...») /М. Горький. Враги/.

Факт нетрадиционных с точки зрения норм современного языка связей слов, своеобразной сочетаемости компонентов, как справедливо отмечает Н. А. Шигаревская (1969, с. 140), представляет собой не «нарушения» синтаксических норм, а «связанный синтаксис». Часто именно такое нарушение правил сочетаемости компонентов предложения указывает на фразеологизацию значения одного из лексических элементов синтаксической конструкции.

К конструкциям с элиминацией словесно выраженной угрозы относятся и конструкции, образованные по модели «Только + у меня [мне] + <ещё [тут, здесь] > + V imper!» (Меликян, 2016, с. 241). Хотя лексемы, обладающие нейтральной оценочностью, легко используются в обоих значениях в функции императива: - На лекции полная тишина, поэтому только тронь ё̈, она и обернётся («тронь...»)/Из разг. речи/; Ср. - Замолчи! А то опояшу разок... - Опояшь! Тронь только, харя твоя бесстыжая!... Только тронь! («не трогай...») /В. Шукшин. Крепкий мужик/. В данном случае синтаксическая конструкция имеет значение передачи положительного, доброго или нейтрального отношения к собеседнику в своем прямом употреблении и негативного - в переносном. Негативное значение наблюдается только в составе сложного предложения или текста, где вторая часть выражает обещаемое следствие. Вторая часть конструкции чаще представляет собой определённо-личное или обобщенно-личное односоставное предложение.

В конструкциях данного типа структурно-семантическая асимметрия обычно обусловлена конкретно-лексическим наполнением и определяется использованием довольно ограниченной группы слов, которые в силу своей семантики обычно накладывают запрет на использование этой модели предложения в прямом, позитивном значении, например: посмей, сунься, подступись, свяжись, наябедничай и некоторые другие, например: - Паршивый чёрт... Насажали вас здесь, иродов, на нашу погибель! - Поругайся мне ещё тут..., - бормочет фельдщер, кладя в шкаб 
щипиы. - Невежа... Мало ли тебя в бурсе берёзой потчевали?! /А. Чехов. Хирургия/; - Вань, ты выйди, спроси дорогу, - насмешливо посоветовал стрелок-радист. - Позубоскаль у меня! - разозлился Дедюхин. /А. Иванов. Вечный зов/.

Таким образом, семиоимпликационные значения неспециализированHых конструкций можно рассматривать как выводимые из кодифицированной семантики данной модели, как заложенные в ней модификации. Специализированные же модели следует, видимо, квалифицировать как варианты построений со свободной структурой. Они также обладают кодифицированным значением, которое может отличаться от семантики производящей конструкции и которое также может предполагать семиоимпликационные процедуры выведения коммуникативного смысла.

Модель предложения как единица синтаксиса «...является объёмной и динамической» (Москальская, 1981, с. 7). Поэтому «процесс конкретизации модели до уровня конкретного речевого факта может быть многоступенчатым...» (Чеснокова, 1973, с. 16). Отсюда, как показал анализ языкового материала, способность выражать два противоположных значения может быть потенциально заложена на различных уровнях конкретизации модели предложения: абстрактном (синтаксическом), морбологическом, обобщённо-лексическом и конкретно-лексическом (т.е. на уровне речевой реализации модели). В силу значимости первых двух из них приведём ещё несколько примеров.

Абстрактный уровень. Изменение нейтрального словопорядка в предложении, в частности, вынесение на первое место одного из членов предложения, способствует переосмыслению его значения на противоположное, например, «Стану [буду, ... ] + Pron 1 + V inf!»: Ермолай никогда ее [собаку] не кормил. - Стануя пса кормить, - рассуждал он, - притом пес-животное умное, сам найдет себе пропитанье! («не стану...»)/И. Тургенев. Ермолай и мельничиха/; Ср. - Когда ты станешь пса кормить вовремя? - Стану я пса кормить, только отстань («стану...»)/Из разг. речи/.

Морфологический уровень. Например, переосмысление значения следующей конструкции обусловлено формой будущего времени предиката: [Жадов:] Вы меня нынче совсем измучили. Замолчи, ради бога. [Полина:] Какже, дожидайся, будуя молчать! («не буду...») /А. Островский. Доходное место/; Ср. - Если ты не будешь молчать, мы пропали! - Буду я молчать, не беспокойся («буду...»)/Из разг. речи/. Значение категории ирреальной модальности, вносимой глаголом-сказуемым, 
также может способствовать переосмыслению ряда синтаксических построений, например, «V imper + ещё!»: - Да ну тебя... Рассказывай ещё!! - отмахнулась мать («не рассказывай...»)/А. Гайдар. Школа/; Ср. - Рассказывай ещё! У тебя так хорошо получается («рассказывай...») /Из разг. речи/.

Явление семиоимпликационной семантики предложений, способных выражать противоположные значения, обусловлено также различного рода факторами общего характера: лингвистическими (асимметрией языкового знака, благодаря которой одна и та же языковая форма способна выражать различное содержание; неразрывным единством рационального и эмоционального в языке; способностью синтаксических конструкций выражать как предметную, так и оценочную семантику; разнообразием контекстуальных средств, которые способны обеспечить актуализацию и реализацию как информативного, так и оценочного аспектов значения) и экстралингвистическими (разнообразием, сложностью и многоаспектностью предметов объективной действительности; неразрывностью логического и оценочного планов в реальной действительности; особенностями человеческой психики, индивидуальным коммуникативным замыслом субъекта речи; разнообразием ситуаций речевого общения).

Описываемые здесь синтаксические конструкции обладают огромным потенциалом экспрессии. Это обусловлено рядом факторов. Во-первых, преимущественным использованием в их арсенале восклицательных по структуре моделей предложений. Во-вторых, использованием «маски» позитивного высказывания при выражении негативного содержания и наоборот, то есть асимметрией формы и содержания, а отсюда - и появлением эффекта неожиданности, всегда связанного с определёнными эмоциями. B-третьих, их эмоциональность определяется функциональным предназначением: такие конструкции, как правило, применяются в качестве эмоционального средства воздействия на собеседника с целью вызвать определённую эмотивную реакцию либо заставить реципиента изменить своё мнение по обсуждаемой проблеме. Подобные задачи предъявляют повышенные требования к используемым моделям в сфере экспрессивности, что приводит к их частому употреблению в живой разговорной речи, где эмоциональный замысел говорящего передается ещё и интонационно. B-четвертых, экспрессивность связана с фактом переносного употребления форм наклонения, времени и лица. Эта особенность в значительной 
степени является следствием расхождения, контраста между контекстом и грамматическим значением глагольной формы.

Говоря о направлении развития явления семиоимпликации в сфере негопозитивной и оценочной противоположности значений предложения, можно утверждать, что в сфере данного языкового факта доминирующим условием является стремление к максимальной выразительности языка, с одной стороны, к однозначности, точности, эффективности - с другой. Тенденция к экономии языковых средств в данном случае оказывается более слабой.

Причина этого процесса заключается в стремлении закрепить данные предложения за сферой экспрессивного синтаксиса благодаря их использованию исключительно во вторичном, ироническом, максимально экспрессивном значении. В качестве подтверждения этого выступает то обстоятельство, что, как правило, несимметричные построения характеризуются наличием целого набора языковых средств, закрепляющих за ними экспрессивно-ироническую функцию.

Его следствием является характер соотношения количества симметричных и несимметричных (однозначных) негопозитивных построений: несимметричных (максимально специализированных) построений примерно в 1,5 раза больше, чем симметричных (со смягченной специализацией) конструкций.

Представляется актуальным исследование данного объектного пространства в функционально-коммуникативном, когнитивном, дискурсивном и прагмалингвистическом аспектах.

Библиография

Ардентов, Б. П. (1976). Конверсивные предложения. In Изучение грамматического строя языка и преподавание грамматики в вузе и школе (Материалы всесоюзной конференции). Кишинев: Штиинца.

Меликян, В. Ю. (2013). Синтаксический фразеологический словарь русского языка [Электронный ресурс]. Москва: Флинта.

Меликян, В. Ю. (2014). Современный русский язык: Синтаксическая фразеология: Учебное пособие. Москва: Флинта.

Меликян, В. Ю. (2016). Словарь экспрессивных устойчивых фраз: Фразеосхемы и устойчивые модели. Москва: Флинта.

Москальская, О. И. (1981). Проблемы системного описания синтаксиса. Москва: Высшая школа. 
Никитин, М. В. (1988). Основы тингвистической теории значения. Москва: Высшая школа.

Никитин, М. В. (1997). Предел семиотики. Вопросы языкознания, 1997(1).

Ноуэлл-Смит, П. Х. (1985). Логика прилагательных (Л. Б. Лебедева, Trans.). In Hoвое в зарубежной лингвистике (Vol. 16). Москва: Прогресс.

Ожегов, С. И., \& Шведова, Н. Ю. (1994). Толковый словарь русского языка. Москва: АЗЬ.

Чеснокова, Л. Д. (1973). Конструкиии с творительным предикативным или его эквивалентами и система членов предложения в современном русском титературном языке (Автореф. на соиск. учен. степени докт. филол. наук). Ленинград.

Шигаревская, Н. А. (1969). О восклицательных предложениях (на мат-ле франц. языка). Вестник ЛГУ, 2(8).

Шмелев, Д. Н. (1958). Экспрессивно-ироническое выражение отрицания и отрицательной оценки в современном русском языке. Вопросы языкознания, 1958(6).

\section{Bibliography (transliteration)}

Ardentov, B. P. (1976). Konversivnye predlozheniia. In Izuchenie grammaticheskogo stroia iazyka i prepodavanie grammatiki v vuze i shkole (Materialy vsesoiuznoĭ konferentsii). Kishinev: Shtiintsa.

Chesnokova, L. D. (1973). Konstruktsii s tvoritel'nym predikativnym ili ego ékvivalentami $i$ sistema chlenov predlozheniia $v$ sovremennom russkom literaturnom iazyke (Avtoref. na soisk. uchen. stepeni dokt. filol. nauk). Leningrad.

Melikian, V. I. (2013). Sintaksicheskiu frazeologicheskiu slovar' russkogo iazyka [Electronic resource]. Moskva: Flinta.

Melikian, V. I. (2014). Sovremennyı̆ russkiŭ iazyk: Sintaksicheskaia frazeologiia: Uchebnoe posobie. Moskva: Flinta.

Melikian, V. I. (2016). Slovar' èkspressivnykh ustoŭchivykh fraz: Frazeoskhemy i ustoŭchivye modeli. Moskva: Flinta.

Moskal'skaia, O. I. (1981). Problemy sistemnogo opisaniia sintaksisa. Moskva: Vysshaia shkola.

Nikitin, M. V. (1988). Osnovy lingvisticheskoŭ teorii znacheniia. Moskva: Vysshaia shkola.

Nikitin, M. V. (1997). Predel semiotiki. Voprosy iazykoznaniia, 1997(1).

Nouell-Smit, P. K. (1985). Logika prilagatel'nykh (L. B. Lebedeva, Trans.). In Novoe v zarubezhno lingvistike (Vol. 16). Moskva: Progress.

Ozhegov, S. I., \& Shvedova, N. I. (1994). Tolkovyı̆ slovar' russkogo iazyka. Moskva: AZ.

Shigarevskaia, N. A. (1969). O vosklitsatel'nykh predlozheniiakh (na mat-le frants. iazyka). Vestnik LGU, 2(8).

Shmelev, D. N. (1958). Ėkspressivno-ironicheskoe vyrazhenie otritsaniia i otritsatel'noŭ otsenki v sovremennom russkom iazyke. Voprosy iazykoznaniia, 1958(6). 


\section{The phenomenon of syntactic semioimplication}

\section{Summary}

Semioimplicative meaning is a "derived," secondary meaning. The typical example of a semioimplicative meaning in syntax is the use of the positive constructions in the meaning of the negative ones and vice versa (converted meaning). The semioimplicative sentence interpretation scarcely has logical limitations. Most sentences, given the right intonation, can undergo an enantiosemic conversion. The ironical negation can be hidden in practically each sentence.

In this article we single out and parameterize the main conditions of such semioimplication and the kinds of language means triggering the semioimplicative mechanism. Besides, we draw attention to the ways of expressing diverse connotations organically linked with the very process of syntactic constructions semioimplication and consistently caused by it.

The core of semioimplicative structures is constituted by constructions that are able to express two meanings: direct and transferred (in this case, opposite) meaning. We have termed them "symmetrical" constructions. The sentence models with one meaning opposite to the form expressing it and also the models opposite in sign but not correlated according to some morphological characteristics serve as the periphery of semioimplication ("nonsymmetrical" constructions).

The models that possess any language means facilitating their reconsideration as their own opposites are called the "specialized" models in the research. The "non-specialized" models do not have such qualities.

The ability to express two opposite meanings can potentially take place on different levels of the sentence model concretization: abstract (syntactic), morphological, general lexical and concrete lexical (i.e., on the level of speech model realization). Each of the types of opposition, both objective and evaluative ones, has its own means of specialization.

In the sphere of enantiosemical and evaluative opposition of the sentence meaning the dominating development line of the semioimplication phenomenon is the pursuit of maximal language expressivity, on the one hand, and of monosemanticity, accuracy, and effectiveness, on the other hand. The tendency toward language means economy turns out to be weak in this case. 
The reason for this process consists in the desire to assign these sentences to the sphere of the expressive syntax by using them exclusively in the secondary, ironical and most expressive meaning. As a result, the nonsymmetrical (the maximally specialized) constructions are 1.5 times more numerous than the symmetrical constructions (ones with moderate specialization).

We find research of this subject-matter in its functional-communicative, cognitive, discoursive and pragmatic-linguistic aspects to be to a topical and worthwhile endeavor.

\section{Zjawisko semioimplikacji składniowej}

\section{Streszczenie}

Znaczenie semioimplikacyjne to znaczenie „pochodne”, wtórne. Typowym przykładem występowania znaczenia semioimplikacyjnego w składni jest używanie konstrukcji pozytywnych w znaczeniu negatywnym i vice versa (konwersja znaczenia). Semioimplikacyjna analiza zdania praktycznie nie napotyka na logiczne ograniczenia. Większość zdań, jeśli towarzyszy im odpowiednia intonacja, w określonych kontekstach może ulegać enantiosemantycznej konwersji: ironiczne zaprzeczenie może skrywać się w praktycznie każdym zdaniu.

W tym artykule identyfikujemy i parametryzujemy podstawowe warunki takiej semioimplikacji oraz rodzaje środków językowych, jakie inicjują mechanizm semioimplikacyjny. Zwracamy także uwagę na sposoby wyrażenia różnorakich konotacji związanych organicznie z samym procesem semioimplikacji struktur składniowych i regularnie przez nią wywoływanych.

Rdzeniem struktur semioimplikacyjnych są konstrukcje mogące wyrażać oba znaczenia: dosłowne i przenośne (tu: przeciwstawne). Określiliśmy takie konstrukcje mianem „symetrycznych”. Za peryferia zbioru konstrukcji semioimplikacyjnych (za konstrukcje „niesymetryczne”) można uznać modele zdań mających tylko jedno znaczenie, które jednak jest przeciwstawne w stosunku do wyrażającej go formy, oraz modele o przeciwnym znaku, ale nieskorelowane pod względem niektórych parametrów morfologicznych.

Modele zdań dysponujące środkami językowymi ułatwiającymi zmianę ich znaczenia na przeciwstawne nazywamy „wyspecjalizowanymi”. Modele „niewyspecjalizowane” nie dysponują takiego rodzaju środkami. 
Zdolność wyrażania dwóch przeciwstawnych znaczeń może potencjalnie zachodzić na różnych poziomach konkretyzacji modelu: abstrakcyjnym (składniowym), morfologicznym, leksykalnym ogólnym i leksykalnym konkretnym (tzn. na poziomie językowej realizacji modelu). Każdy z typów przeciwstawności, czy to przedmiotowej czy wartościującej, dysponuje własnymi środkami specjalizacji.

W sferze enantiosemicznej i wartościującej przeciwstawności znaczeń zdania dominującym kierunkiem rozwoju zjawiska semioimplikacji jest dążenie, z jednej strony, do maksymalnej wyrazistości języka, z drugiej zaś - do jego jednoznaczności, precyzji, efektywności. Tendencja do zwiększania ekonomii środków językowych okazuje się w badanym przypadku słabsza.

Przyczyną tego procesu jest dążenie do trwałego przypisania takich zdań ekspresyjnej sferze składni za sprawą używania ich wyłącznie w drugim, ironicznym, a zarazem bardziej ekspresyjnym znaczeniu. W rezultacie konstrukcji niesymetrycznych (maksymalnie wyspecjalizowanych) jest w przybliżeniu 1,5 raza więcej niż konstrukcji symetrycznych (umiarkowanie wyspecjalizowanych).

Uważamy za wskazane dalsze badania nad zarysowaną tu tematyką w jej aspekcie funkcjonalno-komunikacyjnym, kognitywnym, dyskursywnym i pragmalingwistycznym.

Keywords: semioimplication; enantiosemy; communikeme; fixed phrase scheme; nongrammatism; phraseologisation

Słowa kluczowe: semioimplikacja; enantiosemia; negopozytywność; komunikema; schemat frazeologiczny; agramatyzm; frazeologizacja

(1) Vadim Melikian; Department of Language Theory and Russian Language; Institute of Philology, Journalism and Intercultural Communications; Southern Federal University, Rostov-on-Don - Taganrog

Correspondence: melikyanv@mail.ru

(2) Anna Melikian; Department of Intercultural Communication and Methodology of Foreign Language Instruction; Institute of Philology, Journalism and Intercultural Communications; Southern Federal University, Rostov-on-Don - Taganrog

Correspondence: melikyan.anna@mail.ru

Authors' contribution: concept of the study: Vadim Melikian; data analyses: Anna Melikian; writing and drafting the manuscript: Vadim Melikian and Anna Melikian.

This article was financed at the authors' own expense.

Competing interests: Both authors have declared they have no competing interests. 